\section{RELATION OF MINERAL RESOURCES TO WORLD PEACE*}

\author{
By SIR THOMAS HOLLAND, K.C.S.I., \\ K.C.I.E., F.R.S.
}

\begin{abstract}
MONG the raw materials referred to in the A Atlantic Charter minerals are, beyond question, the most important because of their natural occurrence under fixed geographical conditions which cannot be changed by any artificial measures. They are essential to all technical industries; and, rightly or wrongly, applied technology has become an inevitable and ineradicable phase of our civilization. No civilized community can now exist without a sufficient, and sufficiently varied, supply of mineral products ; substitutes for them cannot be provided, except to a very small degree, by other materials, natural or artificial, without increased cost and loss of efficiency. The demand for them is insistent and certainly will increase in the immediate future. The problems before us are therefore urgent.
\end{abstract}

Yet the workable deposits of useful minerals are distributed without regard to climate or established national boundaries. It follows, consequently, that, so long as difficulties are created among the nations for the exchange of such raw materials, there must always be potential friction between the 'haves' and the 'have nots'. One can even go further without intelligent contradiction and say that, whereas tariffs can hamper international trade in mineral products, no tariff can prevent the trade altogether without the immediate creation of conditions which are certain to lead to war.

It will not be possible here to do more than present one or two illustrations to show the importance of selecting this section of the Atlantic Charter for special discussion; and this limitation to mineral questions does not mean that we fail to recognize the similar significance of other raw materials.

But it is the speed of change in the international bearing of mineral questions which gives them special urgency. During the first thirty-seven years of this century, the output of ordinary steel in the United States increased five times, from about 10 to more than 50 million tons, and, to produce the output for 1937, three fourths of a million tons of manganese ore had to be imported as one constituent among the necessary raw materials. In the latter year, with the help of a protective tariff amounting to about 100 per cent of the import price of manganese ore, the United States did not produce enough of the ore from domestic sources to meet much more than about five per cent of that country's own essential requirements. (In giving these round figures I am not unmindful of the fact that research on methods for concentrating the large deposits of American low-grade ores shows some signs of possible success in times of high prices or during the emergency of war.) You can guess therefore what the result would be if an extension of the recent tendency towards nationalism went so far as to prohibit the export of manganese ore to the United States from the four or five principal sources-the British Empire which then produced one third of the world's total of six million tons, and Russia which produced another third, both countries, especially Russia, wanting a large share of their own

* Substance of the opening address at the Conference on "Mineral Resources and the Atlantic Charter" of the Division for the Social and International Relations of Science of the British Association on July $24-25$. outputs; while France, Germany and Japan, producing between them negligible amounts, wanted most of the remaining third.

Short of absolute prohibition, tariffs might conceivably force the United States to exploit more vigorously its own resources at home and in Cuba, with the result, however, that all known workable high-grade resources at the disposal of the American Government would be effectively exhausted within a few years. The world is so made that the chief steel-making countries - the United States, Great Britain, Germany, France, Italy and Japan-have little more than negligible resources of manganese ore to rely on within their own political boundaries, whereas the countries in which the mineral occurs in greatest abundance are but small consumers of it. During 1937, four fifths of the world's output of steel occurred in countries which produced only about two per cent of the required manganese $\dagger$.

India is now producing about a million tons of steel annually, but uses for the purpose less than two per cent of its own output of manganese ore. Russia thus becomes an outstanding exception; for many years it has been the world's chief producer of manganese, and, unexpectedly to others, during the decade before 1937 increased its output of steel ten times, thus passing from the sixth to the third position among the steel-making countries.

Now we can speculate with some degree of certainty on one important reason why Germany suddenly broke her pact and invaded Russia. It is a prospective shortage of manganese rather than of petroleum which threatens disaster to Germany's munition supplies. Petroleum can be made to some degree and to an increasing extent from the abundant brown coal supplies in Germany itself, although this incurs the absorption of much technical man-power, and nearly sufficient natural supplies are obtainable from other controlled countries, especially Rumania. But of manganese, all the European countries under the domination of Germany cannot together produce more than a fraction of that necessary to feed the steel furnaces under German control. Before the War the countries now under German domination imported annually more than $1 \frac{1}{2}$ million tons of highgrade manganese ore. The most productive among them has never turned out a tenth of this quantity, and even that is of a relatively low grade. Before the War of 1914-18, both France and Germany had accumulated some stocks of manganese, but not nearly enough to see them through, and Germany, being hampered at sea, was finally in serious difficulty.

One cannot, however, be confident in estimating the stocks of manganese still available in countries now under German control, because, while there is evidence that Germany herself was very late in commencing to accumulate stocks of imported ore for emergency use, it is obvious that France began soon after 1922 and continued annually to import far more manganese than was necessary for her output of steel . This is but one of the many ways in which the French people and their Allies have been 'let down' by a few of their weak and treacherous political leaders.

Whatever doubt on this account there may be about Germany's access to reserves of manganese, one can be more certain about her anxiety to exploit some others of the varied mineral resources of the Soviet, and one of these is almost certainly the † Roush, G. A., "Strategic Mineral Supplies" (McGraw-Hill, 1939), p. 38. $\ddagger$ Roush, G. A., op. cit., p. 68 . 
relatively rare metal platinum, which is wanted in fairly large quantities for various war industries as well as for the manufacture of nitrous explosives. Although the output of the precious metal has trebled during the past twenty years, the substantial sources of supply are still under the control of the united democratic nations, Canada producing about a half, Russia about one fifth, America and South Africa between them another fifth, supplemented by smaller quantities from the Republic of Colombia, Belgian Congo and Abyssinia.

The argument which I have used, based on our information about the natural distribution of manganese ore in the world, is no lonely illustration of the fact that the occurrence of mineral raw materials does not coincide even approximately with the ne. tional domains in which industries have been most highly developed. There are others of a similar type on which the continuance of present civilized activities are dependent, and the American Govern. ment, wisely listening to its scientific and technical advisers, has labelled a dozen such minerals, on this account, as strategic, that is, minerals on which the United States depend on outside-sometimes distant -sources, for those supplies which are absolutely necessary to maintain essential industries and therefore to ensure safety in defence.

Manganese came into general use soon after the invention of the Bessemer process in the middle of the last century, and well over 90 per cent of the metal produced in the world is now consumed in steel-smelting. Although the metal is thus consumed only in a way analogous to that of a medicine, there is no known substitute to take its place on a large scale, and so under present war conditions it becomes a 'key' product.

But out of the study of its function in this way, there arose some twenty-five years later a quite different use for the metal as a definite constitutent of the manganese-steel which was invented by the late Sir Robert Hadfield. His invention of manganesesteel opened up a new era in metallurgy, for it became the forerunner of a whole family of alloys of iron with relatively rare elements like cobalt, chromium, molybdenum, nickel and tungsten.

It was the discovery and extended use of these new alloys which changed, and changed on a large scale, the problem of supplies for the industrialized Great Powers. In the last century mechanical industries sprang up around areas containing deposits of the small number of natural products required in the manufacture of ordinary iron and steel ; for example, around the British coalfields, in which there occurred associated supplies of iron ore, limestone flux and coking coal. When the local supplies of ore became exhausted, improved transport facilities enabled Great Britain to bring iron ore from Spain and Scandinavia. But then again when ferro-alloys, with their very special and previously unexpected properties, superseded ordinary steel, their constituents had to be brought from still more distant parts of the earth, and the whole problem of commercial success in industry, as well as security in war, thus assumed an entirely new configuration. For, in addition to the family of ferro-alloys, other metallic alloys of industrial importance were discovered, such as those largely made of aluminium and magnesium, combining low density with sufficient strength for aircraft construction. Nor indeed is the end of this avenue of metallurgical development in sight or even predictable.
A country like Great Britain, which was practically self-contained for the few and simple essential constituents of ordinary steel up to the last quarter of the nineteenth century, quickly found itself dependent on supplies from distant parts of the Empire, and even from foreign competitors. From the happy condition of congratulating itself, the new century found Great Britain, for example, looking to Canada and the Belgian Congo for cobalt, to British Guiana and France for aluminium ore, to Canada for nickel, to India and the Gold Coast for manganese, to China and Burma for tungsten. A new meaning was given to the importance of retaining command of the seas, which seems now to be giving place to command of the air.

These are but a few among many mineral products which are just as essential as imported food for our continued existence as a nation; and indeed more so, because no artificial effort can grow minerals where they have not been placed already by Nature. There are not and never will be available synthetic metals for industrial use. We can use plastic products for door knobs and ash trays to oconomize in imported copper and zinc for brass, but wo cannot economically replace bauxite, which we must import for its aluminium, by aluminous clay which we have in abundance; and generally, while one metal can occasionally be used to replace another at greater cost and reduced efficiency, so far as Great Britain is concerned, we cannot produce even an ine ficient substitute. But Great Britain is not unique in this respect. France, Germany, Italy and Japan, as independent units, are also dependent on the outside world in other ways and to different degrees. Even the United States can never be self-contained. Nor can any country derive comfort and security from its greater approach to self-sufficiency; for what is the use of being able to build a motor-car if we are dependent on another country for a sparking. plug ?

So far I have spoken of essential minerals in qualitstive terms. When we consider the situation quantitatively, the problem takes a much more serious aspect. The extension of our demands in kind is being accom. panied by a correspondingly increased consumption in quantity, with one immediate and dangerous result that smaller deposits of useful minerals must be neglected for richer and larger masses which can be exploited in bulk. The pace in consumption has increased since 1900 on a scale which has resulted in a greater output than the total production of all previous history back to the Stone Age.

This comprehensive statement has been met, I know, with the criticism that statistical records do not extend back beyond the nineteenth century; but its accuracy can be checked by a simple diagram for any representative mineral used in the industrial arts and therefore can be applied to the whole. We might, for example, take a metal like copper as one which is familiar to everyone by its widespread use in a variety of ways. At the beginning of the nineteenth century the world produced about 10,000 tons of copper a year, by the middle of the century about 40,000 tons, and before the century finished, produc. tion had reached half a million tons annually. The curve of production went on rising, with only two serious setbacks, until it indicated in 1937 that the annual output had passed two million tons. It is easy to see that the area of the curve enclosed between 1900 and 1927 must necessarily exceed that of all previous periods sinoe man became a metal- 
lurgist. Similar curves, not always rising so steeply, tell the same story for other familiar metals.

This matter is not mentioned as. a mere curiosity of industrial history : it is to show that, with the growth of national exclusiveness in recent years, there has sprung up an increased interdependence among the nations and especially among the greater Powers, beyond the control and, one can say with safety, beyond the mental comprehension of those politicians who have had most to say, and too much influence, on the international questions which have brought us to the present condition of universal war.

As one result of vague fears of aggressive trespass during the past twenty years, and in spite of isolated attempts to the contrary, the nations have become more and more self-conscious, and, with regard to their natural possessions of minerals, more inclined to conserve their resources. Many of them, the British Empire no less than others, have refused the grant of concessions to prospect for or to exploit mineral deposits, thinking through vague fear that some vital asset may thus be squandered; forgetting, however, that a mineral deposit cannot in an emergency be readily turned to account by the nation itself unless it is already developed, overlooking the fact that, even under war conditions, a mine cannot be taken out of the country in which it lies, and failing to realize that what matters is not the nationality of the mining company which risks its money in prospecting and mining, but in which country the mineral is finally prepared for use in the arts-the arts of peace or the arts of war.

Failure generally to appreciate the fact that civiliza tion cannot go on at all without the international exchange of minerals has developed at times a general atmosphere of tension that cannot be relieved except by war. As no country can ever be self-contained in future for essential mineral raw materials, no nation can contribute its share to the progress of civilization without the operation of principles such as those out. lined in the Atlantic Charter. But for democratic nations to implement those principles, it is necessary for the public to understand far more than they do now the part which mineral problems play in civilized activities.

In the United States the problems have been examined in critical detail for several years by selected committees of technological specialists, hut naturally their chief object has been to provide military security for the nation in a world threatened by potential aggressors.

The Soviet Republics of Russia have done the same by official organizations, and most of the world seems so far to have failed to appreciate the extent of their resources or the realistic thoroughness which has actuated the present Government of the U.S.S.R. in the utilization of applied science.

Fifteen years ago, the J3ritish Empire Council of Mining and Metallurgical Engineers formulated proposals for a similar investigation of our scattered resources, but the Dominion Governments have apparently been dominated by the immediate problems of promoting inter-Empire commerce, and have consequently overlooked the dangers of national exclusiveness regarding mineral raw materials, which all well-behaved nations must reasonably obtain if civilization, such as we know it, is to survive.

At the time of the South African meeting of the British Association, I could see no further than a possible understanding-which is the first necessary step towards agreement-between the United States and tho British Commonwealth, which between them, at the time, controlled three fourths of the world's workable deposits. My imagination takes me in the same direction still, but very little further along the road towards the development of an international conscience about the hoarding of mineral deposits.

Another serious effort should be made to formulate measures for facilitating the international flow of mineral products, keeping always in mind the simple circumstances that no country is or will be selfcontained for mineral supplies, and no development of science can or ever will grow workable mineral deposits where they are not already formed by Nature. And I ought perhaps to repeat what I suggested at the beginning, that this question is by no means a matter of academic interest. It is one that must be settled and settled quickly by practical measures if civilization is to be saved for our descendants. Unless it is settled, and settled quickly at the end of the War, by an intelligent understanding among the successful Powers, newly concocted aggressive attempts to enforce control will lead intermittently to further outbreaks of war. Delay for more mature consideration may be the rashest step to take.

\section{REFLEXION OF X-RAYS WITH CHANGE OF FREQUENCY}

\author{
By $S_{I R}$ C. V. RAMAN, F.R.S. \\ Indian Institute of Science, Bangalore
}

TN Current Science of April, 1940, photographs were 1 published exhibiting the very remarkable phe. nomena observed when a pencil of X-radiation from a copper target traverses a cleavage plate of diamond and the resulting Laue diagrams are recorded with adequate exposures. The photographs showed monochromatic X-ray reflexions from the (111) planes of the crystal which were quite sharply defined at all settings of the crystal but which were evidently different from the well-known Bragg reflexions. As this phenomenon was inexplicable on the existing
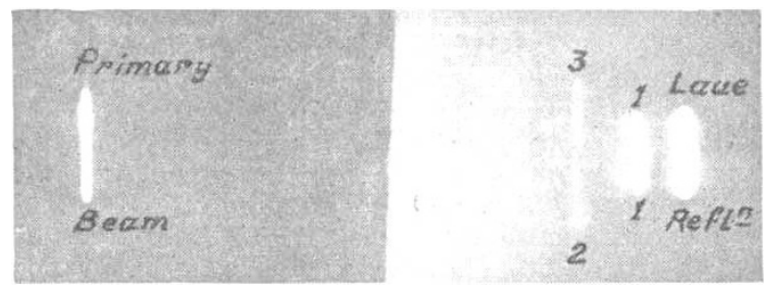

Triple quantum reflexions by the (111) planes in diamond.

X-ray theories, it was interpreted as follows : X-ray photons traversing a crystal can exchange energy with it, giving up or taking on a quantum of energy corresponding to the frequency of one or another of the infra-red or high-frequency vibrations of the crystal lattice; the X-rays are then geometrically reflected by the lattice planes of the crystal with a change of frequency. Further study of the effects exhibited by the (111) planes of diamond showed them to be in complete accord with the ideas outlined in the article of April, 1940 (see accompanying 